\title{
Use of a Digital Chronic Obstructive Pulmonary Disease Respiratory Tracker in a Primary Care Setting: A Feasibility Study
}

\author{
Gerard J. Criner · Therese Cole $\cdot$ Kristen A. Hahn • Kari Kastango • \\ James M. Eudicone · Ileen Gilbert
}

Received: April 7, 2021 / Accepted: July 29, 2021 / Published online: August 31, 2021

(C) The Author(s) 2021

\section{ABSTRACT}

Introduction: Telemonitoring is a promising self-management strategy to improve health care outcomes. This study evaluated real-world adoption of the chronic obstructive pulmonary disease (COPD) Co-Pilot daily symptom

Supplementary Information The online version contains supplementary material available at https:// doi.org/10.1007/s41030-021-00168-3.

\section{G. J. Criner $(\bowtie)$}

Temple University Hospital, Philadelphia, PA, USA

e-mail: gerard.criner@tuhs.temple.edu

T. Cole

IQVIA, Rockville, MD, USA

K. A. Hahn · K. Kastango

IQVIA, Cambridge, MA, USA

J. M. Eudicone · I. Gilbert

AstraZeneca, Wilmington, DE, USA

Present Address:

T. Cole

Advanced Clinical, Deerfield, IL, USA

Present Address:

K. Kastango

Everest Clinical Research, Little Falls, NJ, USA

G. J. Criner

Department of Thoracic Medicine and Surgery,

Lewis Katz School of Medicine At Temple

University, 3500 North Broad Street, Philadelphia,

PA 19140, USA monitoring tool by patients and primary care providers (PCPs).

Methods: An open-label, 6-month, single-arm, multicenter, noninterventional feasibility study enrolled 97 patients aged $\geq 40$ years with symptomatic or poorly controlled COPD and $\geq 10$ pack-year smoking history. Patients received smartphones and training to use the COPD CoPilot application. During the study, patients tracked symptoms daily; an increase in symptom score of $\geq 1.0$ point from baseline (symptom alert) prompted patients to contact their PCP via tollfree number. The primary endpoint was time to clinical recommendation (TTCR) from a symptom alert; adherence to completing daily symptom reports through the COPD Co-Pilot application and patient satisfaction were also measured.

Results: Overall, 87 of 96 patients (90.6\%) received 2142 symptom alerts; 42 alerts (equivalent to $2 \%$ of all symptom alerts) resulted in 23 patients contacting their PCP. Median TTCR was $7.1 \mathrm{~h}$ (interquartile range [IQR]: 4.0-29.9). Among 15 patients using the toll-free number, median TTCR was $2.1 \mathrm{~h}$ (IQR 0.0-7.2) versus 19.6 h (IQR 4.5-45.2) for eight patients using other contact methods. Average COPD Co-Pilot adherence overall was 75.2\% (95\% CI 74.6-75.9). Patients responded favorably regarding the application's ease of use, functionality, and information provided.

Conclusions: The COPD Co-Pilot tool was associated with relatively high levels of adherence, suggesting patients' willingness to 
monitor symptoms daily. Although a limited number of patients initiated PCP contact, patients who used the study-provided toll-free number had substantially shorter median TTCR, suggesting that this tool could help empower patients to better manage their COPD.

Keywords: Chronic obstructive pulmonary disease; Delivery of health care; Patient adherence; Smartphone application; Telemedicine

\section{Key Summary Points}

Why carry out this study?

Integrated care and telemedicine that involve self-management and patient participation may provide valuable information to both patients and physicians to ensure appropriate management of COPD.

This study evaluated the adoption of a daily digital respiratory symptom collection tool, the COPD Co-Pilot, by patients with COPD and their primary care providers in a real-world, primary care setting.

\section{What was learned from this study?}

For patients who initiated contact with their provider, the wait time between a symptom alert given by the application and a receipt of a clinical recommendation was considerably shorter when patients used the toll-free number provided by the application versus other means of contact (median 2.1 $h$ versus $19.6 \mathrm{~h}$ ).

Patients' adherence to the tool was relatively high (approximately 75\%), and both patients and providers were satisfied with the application.

Features in the COPD Co-Pilot could empower patients to better manage their COPD and may help primary care providers respond to patients more efficiently.

\section{INTRODUCTION}

Chronic obstructive pulmonary disease (COPD) is characterized by persistent respiratory symptoms and airflow limitation [1]. COPD contributes substantially to morbidity and mortality in older adults, ranking third in mortality in the United States [2]. Nearly 16 million Americans have been diagnosed with COPD [3], with an estimated 12 million potential cases remaining undiagnosed [2]. Even among those with a confirmed diagnosis, selfmanagement by patients with COPD may not be optimal [4]. Self-management of COPD focuses on early recognition and treatment of exacerbations, smoking cessation, improving exercise and physical activity levels, proper nutrition, medication adherence, and coping skills.

Integrated care and telemedicine that involve self-management and patient participation may be useful in providing valuable information to both patients and physicians to ensure appropriate management of COPD [5]. With this said, previous studies of the effectiveness of mobile health applications and telehealthcare in COPD have reported inconsistent findings, as indicated by multiple systematic reviews, meta-analyses, and overviews of the literature $[4,6-10]$. Recent reviews indicate that implementations of COPD self-management mobile applications have continued to yield mixed results, with only four of 13 studies in one review showing clinical differences between their control and intervention groups [7], and with heterogeneity obscuring potential improvements in outcome measures in the meta-analysis performed $[7,8]$. These observations echo the ambivalent findings of earlier reviews of self-management interventions for patients with COPD $[4,5,9,11]$ : for instance, only two of the five studies analyzed in a prior review demonstrated a reduction in health care utilization; self-management interventions reduced COPD hospitalizations and emergency room visits in both studies, and in 1 of these, there was a trend toward decreased mortality in the treatment group [4]. The other studies that were captured reported negative results: these 
included increased mortality-which suggested that high-risk patients needed earlier assessment by a trained professional, or that selfmanagement may have led to overconfidence and treatment delays-or similar proportions of patients in the treatment and control groups being readmitted with COPD or dying from the disease within 12 months [4]. One of the studies focused on health-related quality of life and showed no benefit of a self-management approach compared to routine monitoring as an adjunct to usual care or usual care alone [4]. Importantly, however, the evidence base in COPD remains less well developed [10], especially compared with those in other chronic diseases such as type 2 diabetes and heart failure [6], and there is considerable variability in both the interventions and outcome measures used in studies of mobile health applications and telehealth in general, which limits comparisons and applications of results and may not fully capture the benefits of this care model $[7,11,12]$. Recommendations for future studies included incorporating telemonitoring to monitor symptoms and disease severity in the home setting and to provide ongoing feedback to the patient [4], as well as evaluating possible benefits in terms of efficiency of care [7].

As evidenced by the variety of technologybased interventions designed for prior studies in COPD, the use of technology to support selfmanagement of chronic respiratory conditions continues to evolve. For instance, in an observational pilot study evaluating the feasibility and short-term effects of a digitalized pulmonary rehabilitation program delivered via a smartphone for severely symptomatic COPD patients, those who completed therapy had significant improvement in health-related quality of life [13]. In a separate 3-week observational cohort study, patients with COPD used a smartphone to complete a daily symptom diary, wore a wrist accelerometer to record physical activity, and completed an activity questionnaire, and users of metered-dose inhalers for rescue were provided with an inhaler sensor [14]. Results from this study emphasized the importance and feasibility of an integrated approach with personal real-time monitoring of respiratory symptoms, physical activity, and rescue medication in patients with COPD. A more recently reported randomized feasibility study that evaluated a different mobile health intervention for COPD, delivered via a smartphone application and activity tracker in 30 patients, showed promise in helping some patients self-manage their activity levels, although many patients experienced difficulty using the technology [15]. Taken together, the existing evidence base favors interventions that employ easy-to-use technologies and enable patient participation and integrative care.

The COPD Co-Pilot is an easy-to-use smartphone application for real-world monitoring of disease symptoms [16, 17]. The application collects patient-reported daily respiratory symptoms and peak expiratory flow to calculate a symptom score; this is compared to a baseline value that reflects symptoms during the patient's usual state of health. An elevated symptom score of 1.0 point or higher from baseline generates an alert to the patient to contact their health care provider. In a 2-year randomized controlled trial, patients hospitalized for a COPD exacerbation within the past year or using supplemental oxygen were randomly assigned to an intervention group, who reported their symptoms and peak flow readings daily using an electronic diary, or a control group (usual medical care) [16]. Symptom scores in the intervention group were assessed and compared with initial values using a computer algorithm, and patients were alerted to call the office if symptoms worsened. The symptom reporting application identified variability in patients' symptoms and facilitated early treatment and improved lung function, although there were no differences in hospitalization and mortality rates between groups [16].

The goal of this study was to evaluate the adoption of the COPD Co-Pilot daily digital respiratory symptom collection tool by patients with COPD and their primary care providers (PCPs) in a real-world, primary care setting. The primary endpoint evaluated the time to clinical recommendation, which was defined as the time elapsed between the patient first receiving a symptom alert from the tool and the patient receiving a clinical recommendation from the PCP. Specifically, the study assessed the elapsed 
time between when patients contacted their PCP after receiving feedback from the tool (patient response time) and how quickly patients received a clinical recommendation from their PCP in response to their contact (HCP response time). Adherence to completing daily symptom reports through the COPD Co-Pilot application and patient satisfaction were also measured.

\section{METHODS}

\section{Study Design and Patient Population}

This open-label, 6-month, single-arm, multicenter, noninterventional feasibility study was conducted at seven study sites in the United States (Supplemental Table). Study sites were specifically required to be primary care sites with research experience, rather than specialists, and were selected based on completion of a feasibility questionnaire and a Site Qualification visit. This study was reviewed and approved by the Copernicus Group Institutional Review Board, under an abbreviated investigational device exemption as described within applicable Food and Drug Administration regulations. Because all study sites were in the United States, this approval was sufficient for all participating study sites. The study was conducted in compliance with the principles of the Declaration of Helsinki and Good Clinical Practice guidelines.

Patient subjects were recruited to this study by using study site databases to identify patients who would fit the eligibility criteria defined by the study protocol. Male and female outpatients aged $\geq 40$ years with $a \geq 10$ pack-year smoking history and a diagnosis of symptomatic or poorly controlled COPD were eligible for study enrollment. Symptomatic or poorly controlled COPD was defined as $\geq 1$ of the following: (1) a single exacerbation in the previous 12 months requiring treatment with systemic steroids and/ or antibiotics, a postbronchodilator forced expiratory volume in $1 \mathrm{~s}\left(\mathrm{FEV}_{1}\right) /$ forced vital capacity (FVC) ratio $<0.7$, and a postbronchodilator $\mathrm{FEV}_{1}$ of $<50 \%$ of predicted normal in the previous 36 months; (2) $\geq 2$ exacerbations in the previous 12 months requiring treatment with systemic steroids and/or antibiotics separated by $\geq 7$ days, a postbronchodilator $\mathrm{FEV}_{1} / \mathrm{FVC}<0.7$, and a postbronchodilator $\mathrm{FEV}_{1}$ of $\leq 70 \%$ of predicted normal in the previous 36 months; or (3) $\geq 1$ hospitalization for $>24 \mathrm{~h}$ in the previous 12 months, a postbronchodilator $\mathrm{FEV}_{1} / \mathrm{FVC}<0.7$, and a postbronchodilator $\mathrm{FEV}_{1}$ of $\leq 70 \%$ of predicted normal in the previous 36 months. Patients were required to be receiving a stable dose of inhaled corticosteroid/long-acting $\beta_{2}$-agonist indicated for COPD for $\geq 60$ days prior to and for the duration of the study. Patients with an acute exacerbation of COPD that required hospitalization, an emergency department visit, or treatment with systemic steroids and/or antibiotics within 28 days of the first study visit were excluded. Use of maintenance systemic steroids (daily or every other day for $\geq 14$ days) for inflammatory or immunological conditions unrelated to COPD was not permitted.

All patients provided written informed consent and then received a peak flow meter and study smartphone with the HGE (Telford, PA, USA) COPD Co-Pilot daily symptom reporting application preloaded. Both the smartphone application and its accompanying web portal were encrypted, password-protected, and Health Insurance Portability and Accountability Act (HIPAA)-compliant. When patients opened this application, a screen appeared that prompted them to rate their breathlessness (0-10, with 0 being none) as well as their sputum quantity (none, less than 1 tablespoon, 1 tablespoon or more, greater than $1 / 4$ cup), color (white, yellow, green, brown), and consistency (watery, thin, thick). These rating options were accompanied by visual icons to help patients benchmark the descriptors. They were also prompted to enter three attempted peak flow measurement values and to indicate whether they were experiencing any symptoms from a panel of preset items such as coughing and wheezing. Their responses were then summarized and submitted to the portal. Upon submission, the application notified them of their symptom deviation, if any, and/or prompted them to contact their study physician if they exceeded the deviation threshold. All patients received training on the use of this symptomreporting application, including instruction on 
how to perform daily symptom reporting; how to access their 30-day symptom data history; how to use the peak flow meter to measure and report this specific daily symptom; and how to use the toll-free number programmed into the smartphone to contact their PCP during the study in the event of a symptom alert. Additionally, patients then completed their first daily symptom entry at the first study visit, and the site confirmed that there were no service issues. Subsequently, patients received oncedaily reminders to report their respiratory COPD symptoms and received feedback from the system when they did not complete a report. An online web portal allowed PCPs, if they so desired, to have real-time access to patients' daily reported symptoms and peak expiratory flow measured by the study-provided meter.

A 14-day run-in period included a follow-up telephone call 48 to $72 \mathrm{~h}$ after enrollment to check for technology issues and the need for retraining, with another call after 14 days to determine if a valid baseline symptom score calculation was completed. A patient's baseline symptom score was calculated using $\geq 10$ of 14 days of all symptom reports completed during run-in. Patients who experienced an exacerbation during the run-in period were not randomized. During the treatment period, patients completed daily symptom tracking using the COPD Co-Pilot application. Tracked symptoms consisted of the following: breathlessness, peak flow, sputum quantity, sputum color, sputum consistency, temperature $>100^{\circ} \mathrm{F}$, nasal congestion, cough, wheeze, and sore throat. A daily symptom score was considered elevated when a patient's current daily symptom score was $\geq 1.0$ point higher compared with their baseline. Mild, moderate, and severe symptom elevations were categorized as 1.0 to $1.5,2.0$ to 2.5 , and $\geq 3.0$ point(s) higher, respectively, compared with their baseline; scores $>1.5$ to $<2.0$ and $>2.5$ to $<3.0$ were not attainable as a consequence of the scoring algorithm. All symptom scores $\geq 1.0$ point higher than baseline triggered an alert prompting patients to call the dedicated toll-free number to reach their PCP. Calls could be made to this toll-free number at any time.
The routed call would be answered if made during normal business hours; after hours and on holidays, calls were routed to the clinical practice's main number and received the same message as patients calling the practice directly. The recorded message always started with a statement indicating to call 911 for medical emergencies.

Eleven months after the first patient was enrolled, a text change was implemented in the COPD Co-Pilot application and patient guide. Upon successful submission of symptoms, if the application detected a symptom deviation, the final instructions first indicated to call their health care provider immediately to notify them of their score, to continue to take their medication as instructed, and to remember to report again tomorrow; the instructions also indicated to call 911 in case of an emergency. This change clarified the help text displayed, encouraging patients to use the COPD Co-Pilot and to contact physicians appropriately when necessary.

\section{Assessments}

The first primary endpoint was time to clinical recommendation (TTCR), defined as the complete cycle time starting from when the patient received a symptom alert from COPD Co-Pilot prompting them to contact their PCP to the time a clinical recommendation was communicated to the patient by their PCP (Fig. 1). The second primary endpoint was patient adherence to completing the daily symptom reports through the COPD Co-Pilot application. Patients also completed the Patient and Physician Feedback Questionnaire at the end of the study, in which they ranked their experience and satisfaction with using the COPD Co-Pilot application on a Likert scale. The questionnaire included items on ease of use of the device, software, and willingness to use the application long-term. Per study design, up to two PCPs at each study site completed this questionnaire at the end of the study about their experience and satisfaction with using the web portal and service. 


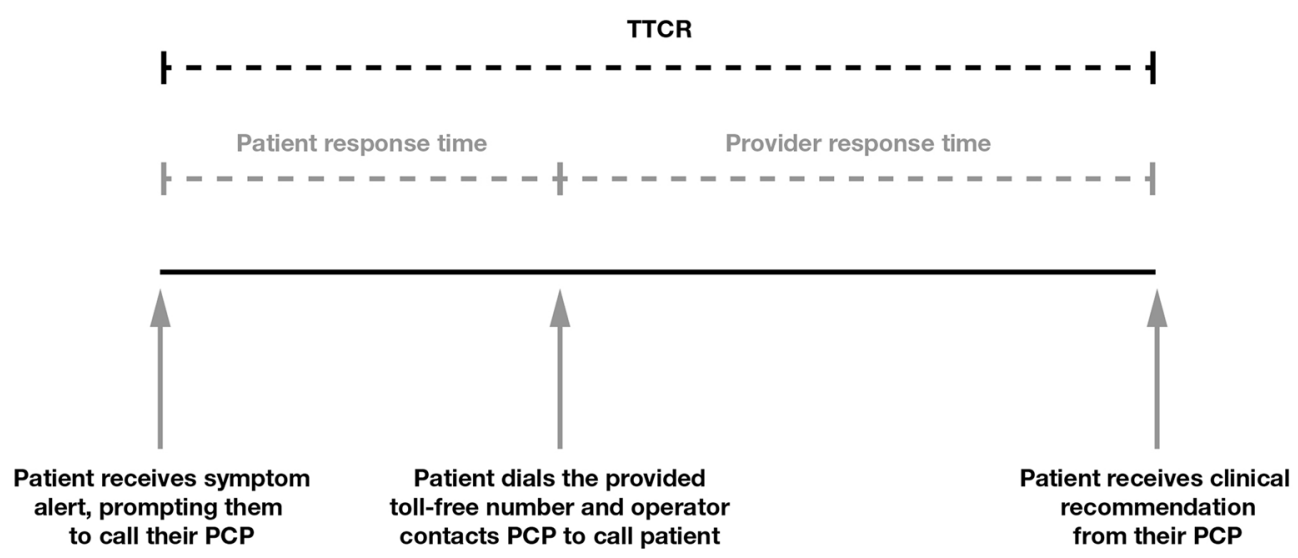

Fig. 1 Diagram of TTCR. PCP primary care provider, TTCR time to clinical recommendation

\section{Statistical Analyses}

The full analysis set (FAS) included all screened patients with COPD who were enrolled in the study. All primary endpoints were analyzed using the FAS. The per-protocol analysis set (PPAS) included patients from the FAS who met all eligibility criteria, had daily symptom tracker reporting adherence $\geq 80 \%$ throughout the study period, and had no major protocol deviations. The primary endpoint of TTCR was also analyzed using the PPAS.

The study planned to enroll $\geq 97$ patients to yield $\geq 70$ completed patients, which would lead to an anticipated 12\% margin of error for the primary outcome measures of TTCR and adherence. The final number of 97 evaluable patients (87 completed patients) for the FAS and 46 patients for the PPAS resulted in margins of error of $\leq 11 \%$ and $\leq 14 \%$, respectively.

Descriptive statistics were computed for patient demographics, medical and COPD history, and the primary endpoints. TTCR was computed for each event during which a patient received a symptom alert from COPD Co-Pilot, contacted their PCP, and was given a clinical recommendation. Categorical characteristics were compared using a Fisher's exact test if they contained row counts $<5$ and a Chi-squared test if otherwise. Continuous characteristics were compared between treatment groups using a $t$ test; parametric assumptions were first tested and met. Adherence was defined as the number of symptom reports actually completed divided by the expected number of symptom reports to be completed $\times 100$ and calculated for the entire length of the study and for each 30-day period. Regression modeling using analysis of covariance was performed on this endpoint.

\section{RESULTS}

\section{Patient Demographics}

A total of 97 patients who recorded $\geq 1$ symptom report were included in the FAS (Table 1). An average of 1.7 COPD exacerbations occurred within the 12 months prior to study baseline, and $16(16.5 \%)$ of patients had been hospitalized for $>24 \mathrm{~h}$ during this time period due to an exacerbation. All clinical recommendation-related outcomes are based on 96 patients; one FAS patient was excluded from these outcomes for not having a reliable baseline symptom score to determine elevated symptom scores and associated symptom alerts.

\section{Primary Endpoints}

Of all symptom reports $(n=12,342), 2142$ $(17.4 \%)$ were considered elevated above baseline, and patients were prompted to contact their PCP via the study-established toll-free number (Table 2). Of the 2142 symptom alerts, 42 (equivalent to $2 \%$ of all symptom alerts) resulted in a call to the patient's PCP via the toll-free number. Among the 87 patients $(90.6 \%$ 
Table 1 Patient demographics and clinical characteristics

\begin{tabular}{|c|c|}
\hline Characteristic & $\begin{array}{l}\text { FAS population } \\
(n=97)\end{array}$ \\
\hline \multicolumn{2}{|l|}{ Age at enrollment (years) } \\
\hline Mean (SD) & $64.6(9.74)$ \\
\hline \multicolumn{2}{|l|}{ Sex, $n(\%)$} \\
\hline Male & $47(48.5)$ \\
\hline Female & $50(51.5)$ \\
\hline \multicolumn{2}{|l|}{ Race, $n(\%)$} \\
\hline White & $87(89.7)$ \\
\hline Black or African American & $9(9.3)$ \\
\hline American Indian or American Native & $1(1.0)$ \\
\hline \multicolumn{2}{|l|}{ Ethnicity, $n(\%)$} \\
\hline Hispanic or Latino & $5(5.2)$ \\
\hline \multicolumn{2}{|l|}{ Smoking status, $n$ (\%) } \\
\hline Current & $41(42.3)$ \\
\hline Former & $56(57.7)$ \\
\hline Number of pack-years, mean (SD) & $42.5(21.0)$ \\
\hline \multicolumn{2}{|l|}{$\begin{array}{l}\text { Number of COPD exacerbations } \\
\text { within the last } 12 \text { months }\end{array}$} \\
\hline (moderate or severe), mean (SD) & $1.7(0.8)$ \\
\hline $\begin{array}{l}\text { Most recent postbronchodilator } \\
\mathrm{FEV}_{1} \% \text { predicted, mean }(\mathrm{SD})\end{array}$ & $43.8(12.5)$ \\
\hline $\begin{array}{l}\text { Most recent postbronchodilator } \\
\mathrm{FEV}_{1} / \mathrm{FVC} \text { ratio, mean }(\mathrm{SD})\end{array}$ & $0.5(0.1)$ \\
\hline $\begin{array}{l}\text { Patients hospitalized for }>24 \mathrm{~h} \text { for } \\
\text { any exacerbation within the last } \\
12 \text { months, } n(\%)\end{array}$ & $16(16.5)$ \\
\hline \multicolumn{2}{|l|}{$\begin{array}{l}\text { COPD medication type for } \\
\text { exacerbation, } n(\%)\end{array}$} \\
\hline Antibiotics & $16(16.5)$ \\
\hline Steroids & $19(19.6)$ \\
\hline Antibiotics and steroids & $61(62.9)$ \\
\hline Other & $1(1.0)$ \\
\hline $\begin{array}{l}\text { Patients taking inhaled respiratory } \\
\text { medications }{ }^{\mathrm{a}}, n(\%)\end{array}$ & \\
\hline
\end{tabular}

Table 1 continued

\begin{tabular}{|c|c|}
\hline Characteristic & $\begin{array}{l}\text { FAS population } \\
(n=97)\end{array}$ \\
\hline Budesonide/formoterol fumarate & $36(37.1)$ \\
\hline Fluticasone furoate/vilanterol & $42(43.3)$ \\
\hline Fluticasone propionate & $6(6.2)$ \\
\hline Fluticasone propionate/salmeterol & $21(21.6)$ \\
\hline Ipratropium bromide & $6(6.2)$ \\
\hline $\begin{array}{l}\text { Ipratropium bromide/albuterol } \\
\text { sulfate }\end{array}$ & $9(9.3)$ \\
\hline Albuterol & $77(79.4)$ \\
\hline Tiotropium bromide & $32(33.0)$ \\
\hline Umeclidinium bromide & $10(10.3)$ \\
\hline Patients prescribed oxygen, $n$ (\%) & $10(10.3)$ \\
\hline $\begin{array}{l}\text { Patients with } \geq 1 \text { comorbid medical } \\
\text { condition, } n(\%)\end{array}$ & $96(99.0)$ \\
\hline $\begin{array}{l}\text { Patients currently taking medication } \\
\text { for condition, } n(\%)\end{array}$ & $91(94.8)^{\mathrm{b}}$ \\
\hline Cardiac disorders & $16(17.6)$ \\
\hline Endocrine disorders & $13(14.3)$ \\
\hline Metabolism and nutrition disorders & $40(44.0)$ \\
\hline $\begin{array}{l}\text { Musculoskeletal and connective } \\
\text { tissue disorders }\end{array}$ & $40(44.0)$ \\
\hline $\begin{array}{l}\text { Respiratory, thoracic, and mediastinal } \\
\text { disorders }\end{array}$ & $16(17.6)$ \\
\hline Vascular disorders & $56(61.5)$ \\
\hline $\begin{array}{l}\text { Patients not taking medication for } \\
\text { condition, } n(\%)\end{array}$ & $75(78.1)^{\mathrm{b}}$ \\
\hline Cardiac disorders & $15(20.0)$ \\
\hline Endocrine disorders & $5(6.7)$ \\
\hline Metabolism and nutrition disorders & $18(24.0)$ \\
\hline $\begin{array}{l}\text { Musculoskeletal and connective } \\
\text { tissue disorders }\end{array}$ & $34(45.3)$ \\
\hline $\begin{array}{l}\text { Respiratory, thoracic, and mediastinal } \\
\text { disorders }\end{array}$ & $13(17.3)$ \\
\hline
\end{tabular}


Table 1 continued

\begin{tabular}{|c|c|}
\hline Characteristic & $\begin{array}{l}\text { FAS population } \\
(n=97)\end{array}$ \\
\hline Vascular disorders & $8(10.7)$ \\
\hline \multicolumn{2}{|c|}{$\begin{array}{l}C O P D \text { chronic obstructive pulmonary disease, } F A S \text { full } \\
\text { analysis set, } F E V_{1} \text { forced expiratory volume in } 1 \mathrm{~s}, F V C \\
\text { forced vital capacity, } S D \text { standard deviation } \\
\text { a Only medications taken by } \geq 5 \% \text { of patients are shown. } \\
\text { Other respiratory medications taken by }<5 \% \text { of patients } \\
\text { in this study were as follows: salbutamol sulfate, } 1(1.0 \%) \text {; } \\
\text { aclidinium bromide, } 3(3.0 \%) \text {; umeclidinium bromide/vi- } \\
\text { lanterol trifenatate, } 1 \text { ( } 1.0 \%) \text {; formoterol fumarate, } 1 \\
\text { (1.0\%); and levosalbutamol tartrate, } 1 \text { ( } 1.0 \%)\end{array}$} \\
\hline
\end{tabular}

of the FAS) who received a symptom alert, 23 (24.0\% of the FAS) initiated PCP contact. Of these 23 patients, 15 (15.6\% of the FAS) used the toll-free number and $8(8.3 \%$ of the FAS) used other methods to contact their PCP.

Following the 42 calls to PCPs, 36 recommendations were made for 20 patients, for an average of 1.8 clinical recommendations per patient. The median TTCR among patients in the FAS who received a recommendation was $7.1 \mathrm{~h}$ (interquartile range [IQR]: 4.0-29.9; Table 2). For patients who initiated contact through the toll-free number (11 recommendations among six patients), the median TTCR was $2.1 \mathrm{~h}$ (IQR 0.0-7.2; Table 2). Median TTCR was $19.6 \mathrm{~h}$ (IQR 4.5-45.3) for recommendations obtained by other means of contact from the patient to the PCP (23 recommendations among 14 patients). Results were similar for the PPAS (data not shown).

The 23 patients who initiated PCP contact (by the toll-free number or other means) in response to a symptom alert had a greater mean number of COPD exacerbations (moderate and severe) in the prior 12 months (2; standard deviation [SD] 0.93; range, 1-4) than the 63 patients who did not contact their PCP after receiving an alert (1.5; SD 0.78; range, 0-4; $P=0.011$ ). These 23 patients responded to the alert by contacting their PCP quickly, within a median time of $2.2 \mathrm{~min}$ (IQR 1.2-32.0).

Most of the symptoms that prompted a call to PCPs were mild in severity. An analysis of patient response time by severity of symptoms is shown in Fig. 2. One specific symptom alert associated with contacting a PCP was elevated body temperature. Of 36 elevated symptom reports that were followed by a call and received a clinical recommendation, seven (19.4\%) indicated a body temperature $>100^{\circ} \mathrm{F}$, as compared with $73(3.5 \%)$ of the 2106 reports that did not generate a call $(P<0.001)$. Most recommendations resulted in no change to COPD treatment without a visit to the PCP (41.7\%; Fig. 3).

\section{Daily Symptom Tracker Adherence}

In the FAS population, there were 16,387 patient study days and 12,342 symptom score reports submitted. In this population, average patient adherence to the COPD Co-Pilot tool was relatively high at $75.2 \%$ (95\% CI 74.6-75.9). When analyzed by each 30-day period, adherence was $\geq 80 \%$ for the first, second, and third 30-day periods and declined each 30-day period thereafter (Fig. 4).

Within the FAS population, patients aged $\geq 65$ years had significantly higher adherence with daily symptom reporting compared with younger patients (82.3 vs. $67.7 \%$; $P=0.002)$. No significant differences in adherence were observed among other patient characteristics, including race, sex, and smoking status at baseline.

\section{Satisfaction Surveys}

The majority of patients favorably rated (agree/ strongly agree) the COPD Co-Pilot system with regard to ease of use, easy-to-understand information, and expected features. Most patients indicated that they would continue using the application and that PCPs were available and responsive when needed (Fig. 5). PCPs responded similarly to satisfaction surveys, reporting the application's ease of use, effectiveness in alerting patients, and measuring true symptom change. Although only two PCPs per site were permitted to complete the survey, the number of PCPs who completed the satisfaction survey was high (14/14). 
Table 2 Clinical recommendations summary

FAS population $(n=96)$

Clinical recommendations made, $n$

36

Patients given a clinical recommendation, $n$ (\%)

$20(20.8)$

Number of clinical recommendations made per patient ${ }^{a}$, mean (SD)

$1.8(1.7)$

Patients with a symptom alert ${ }^{\mathrm{b}}, n(\%)$

Elevated symptom score reports ${ }^{\mathrm{b}}, n(\%)$ $2142(17.4)^{c}$

Patient treatment days with an elevated symptom score ${ }^{\mathrm{b}, \mathrm{d}}$, (\%)

Clinical recommendation $(n=36)^{\mathrm{e}}, n(\%)$

Transfer toll-free call

Connected toll-free call

Did not use toll-free number

Time to clinical recommendation $(n=34)^{\mathrm{f}}$, (h)

Median (IQR)

Time to clinical recommendation by toll-free number $(n=11)^{\mathrm{f}}$, (h)

Median (IQR)

Time to clinical recommendation by other form of contact $(n=23)^{\mathrm{f}}$, (h)

Median (IQR)

$19.6(4.5-45.3)$

$F A S$ full analysis set, $I Q R$ interquartile range, $S D$ standard deviation

a Only calculated for patients given a clinical recommendation

b A daily symptom score is considered elevated (symptom alert) when a patient's current daily symptom score is $\geq 1.0$ point $(s)$ higher compared with their baseline symptom score

$c$ Out of a total of 12,342 symptom reports

${ }^{\mathrm{d}}$ Patient days with an elevated symptom score $=$ (number of elevated symptom score reports/sum of patients' time on treatment) $\times 100$

e Clinical recommendations were received by 20 patients

${ }^{f}$ Time to clinical recommendation is calculated only for 34 clinical recommendations that were documented in the electronic data capture; 2 calls were not captured in the electronic data capture

\section{DISCUSSION}

Prior studies have shown that telemonitoring can enhance self-management of chronic diseases like COPD, especially for high-risk patients $[18,19]$. Although it is not clear which patients with COPD may benefit most from telemonitoring, patients with more severe disease may benefit by controlling the progression of their disease though earlier identification and treatment of exacerbations. In our feasibility study of the COPD Co-Pilot application, the patients who contacted their PCP following a symptom alert had more moderate and severe COPD exacerbations in the prior year compared with those who did not contact their PCP after receiving an alert. These data are consistent with a literature review showing the best telemonitoring outcomes were observed in older and sick patients with more frequent exacerbations [20]. 


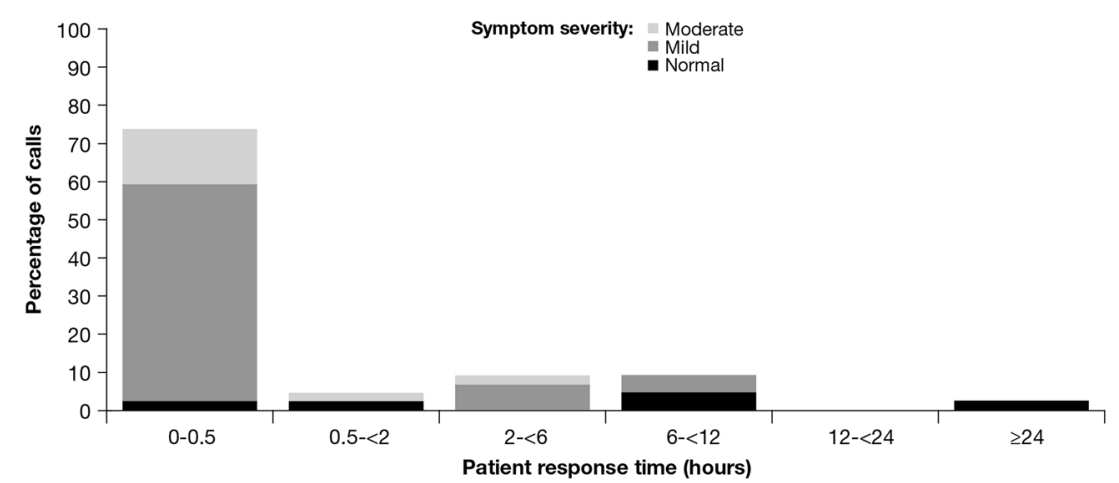

Fig. 2 Patient response time (hours) $^{\mathrm{a}}$ by symptom severity $^{\mathrm{b}}$ that prompted a call to their PCP: FAS. FAS full analysis set, $P C P$ primary care provider. ${ }^{a}$ Patient response time calculated only for those patients who used the toll-free number. ${ }^{b}$ Normal $=$ no elevation in symptom score beyond the threshold of 1.0; mild = an elevation in symptom score between 1.0 and $1.5 ;$ moderate $=$ an elevation in symptom score between 2.0 and 2.5

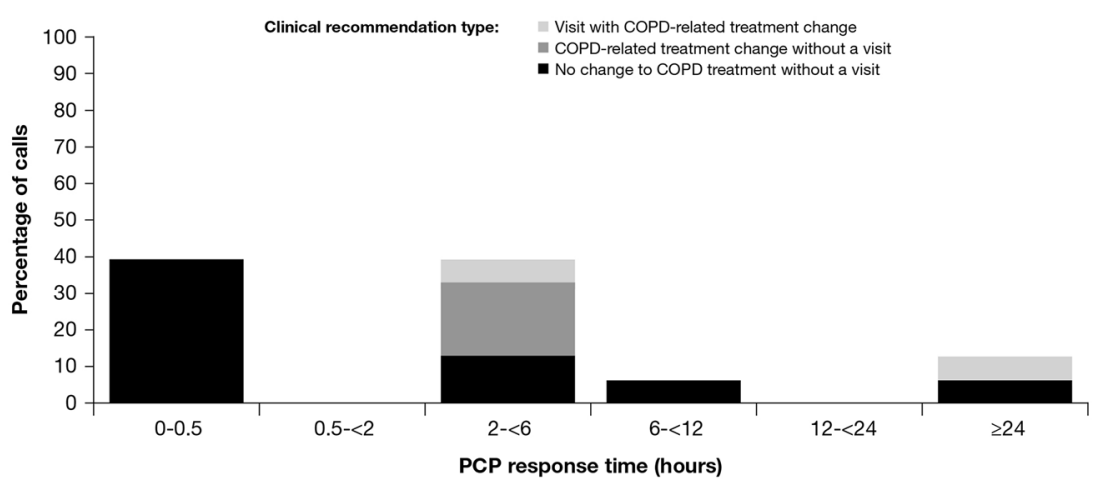

Fig. 3 PCP response time (hours) by clinical recommendation type: FAS. COPD chronic obstructive pulmonary disease, FAS full analysis set, $P C P$ primary care provider

Patients who used the dedicated toll-free number received a clinical recommendation in approximately $2 \mathrm{~h}$, which was more than nine times faster than those who contacted their PCP by other means. These faster response times suggest that providing patients with a dedicated method to contact their provider may especially aid in management of more severe COPD when earlier intervention is often needed. However, the overall number of patients initiating PCP contact in response to symptom alerts was relatively low: 23 of 87 patients. There were no differences in patient age, race, or sex between those who contacted their PCP and those who did not after receiving a symptom alert. Most symptom alerts were mild in severity and most recommendations therefore resulted in no change to COPD medications without a visit to the patient's PCP. Therefore, it is possible that the symptom alert threshold at which patients were instructed to contact their PCP was set too low in this study, prompting patients to call when no therapy adjustment was needed. These results can inform future investigations to improve this application to ensure the identification of worrisome COPD symptoms that should be reported to a provider. Interestingly, the symptom of elevated body temperature led to more frequent PCP contact than other elevated symptoms. Although elevated temperature is not considered part of the symptom complex indicating an exacerbation of COPD, it might signal viral illness or bacterial pneumonia. Concern about worsening symptoms and 


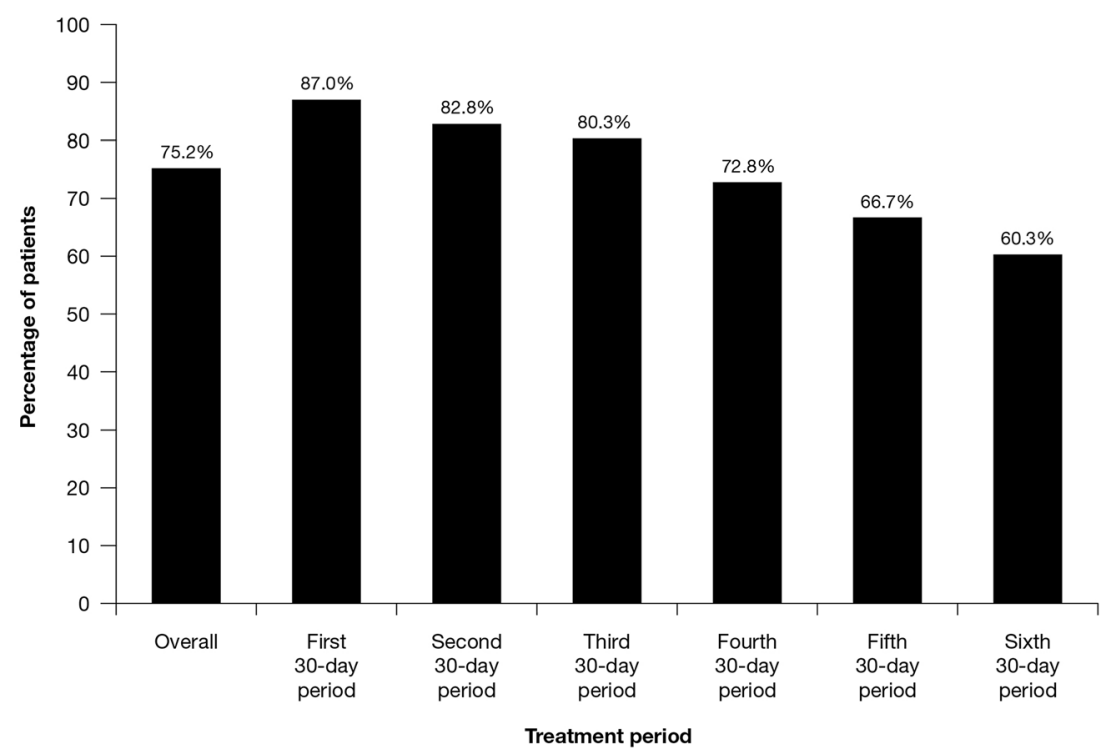

Fig.4 Average patient adherence for the entire treatment period: FAS. FAS full analysis set

prevention of a more serious event may have motivated patients with an elevated temperature to call their PCP.

Average patient adherence to daily symptom reporting using the COPD Co-Pilot application was relatively high at approximately $75 \%$. In a small quality assurance study of the application, 30 patients with COPD at high risk of an acute exacerbation had a mean reporting adherence of $85.6 \%$ [17]. These results indicate that many patients with COPD in primary care are willing to monitor their symptoms daily. In addition, patients in this study aged $\geq 65$ years had a higher adherence rate than younger patients, suggesting that older patients are receptive to digital-based health technology.

The majority of patients and providers had a positive view of the COPD Co-Pilot application, providing strong support for its ease of use and clean design. Most patients indicated that they would continue to use the application and felt that their PCP was responsive. Most PCPs also agreed that the application was an effective way to alert patients and measured true symptom change. Symptom reporting using the COPD Co-Pilot application required minimal interaction with the smartphone, limiting disruptions to an individual's daily activities [17]. These factors may be associated with high adherence and acceptance of the system. Although average adherence over the full course of the study was relatively high, adherence did decrease for each 30-day period for the duration of the study, indicating the importance of PCPs reinforcing the benefits of self-management during regular office visits.

In a systematic review of telemonitoring in COPD that specifically evaluated patient adherence and satisfaction [21], higher adherence rates were associated with daily data transmission compared with more frequent transmissions, and most dropouts were related to usability problems, including technical issues with the system or telephone line. Patients reported improved self-management with the use of various telemonitoring systems and greater involvement in their health care. The systems also helped patients improve communications with their providers. The COPD CoPilot tool incorporates some of the key characteristics identified in this systematic review by being easy to use and facilitated with sufficient training. The inclusion of a 14 -day run-in period ensured that patients understood how the symptom reporting tool worked and gave them an opportunity to use it and get comfortable with it prior to collection of study data. 


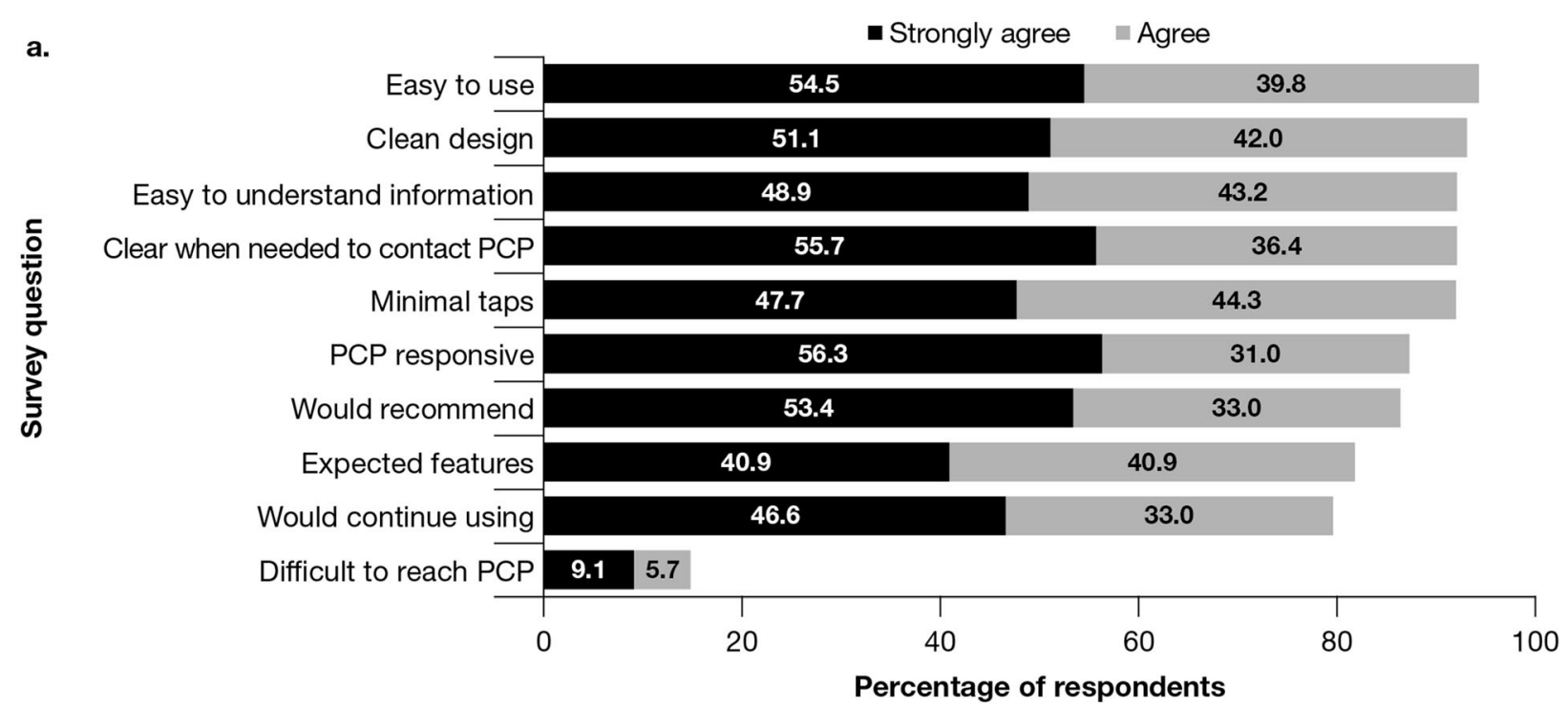

b.

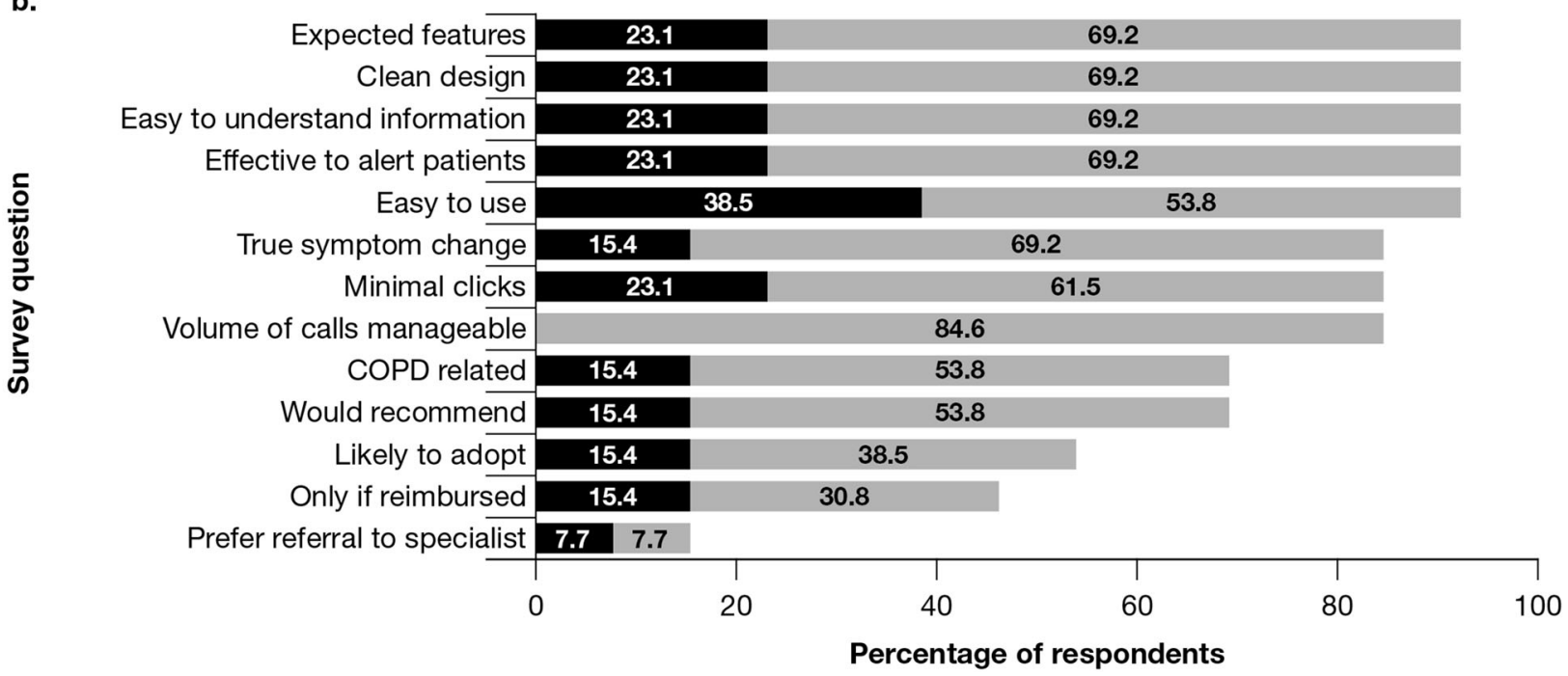

Fig. 5 a Patient $(n=88)$ and $\mathbf{b}$ PCP $(n=14)$ satisfaction with the COPD Co-Pilot application and portal ${ }^{a}$. COPD chronic obstructive pulmonary disease, $P C P$ primary care

This study has several limitations. The number of patients with moderate or severe exacerbations was low, possibly because the patient population was not selected specifically for those with a history of exacerbations. Furthermore, the patients were only followed for 6 months, which may have resulted in the lower frequency of only mild-to-moderate increases in respiratory symptoms from patients' baseline. Extending the study to 12 months would have ensured that all patients provider. ${ }^{\mathrm{a}}$ Other possible responses were indifferent, disagree, or strongly disagree (not shown)

were part of the study during winter months, when COPD exacerbations are most common. The number of patients who received a clinical recommendation was low, limiting the robustness of any comparisons. The reasons that all calls did not result in clinical recommendations were not investigated as part of this study but may have included situations such as a patient calling and hanging up or contacting the site outside of business hours and not leaving a message. In addition, the study did not capture 
the reason why some patients chose not to call their PCP following a symptom alert, nor the type of "transfer" that occurred for calls to PCPs from the toll-free system. The clarification of text in the COPD Co-Pilot application midstudy may have impacted results by increasing patients' willingness to call the toll-free number. More broadly, although the results of this feasibility study are promising, they do not include downstream measures of the effects of application use on overall health care resource utilization among patients with COPD. Additional studies are needed to further demonstrate the value of this application to patients, providers, and payers.

Self-management programs have the potential to improve health care outcomes associated with COPD. In this feasibility study of the COPD Co-Pilot smartphone application for daily symptom monitoring, overall patient contact with PCPs in response to symptom alerts over the course of the study was low and may have been related to patient selection and mild symptom severity. However, when patients contacted their PCP using the toll-free number, the median TTCR of $2.1 \mathrm{~h}$ was considerably faster than the TTCR for patients using other means of contact, which may translate into increased empowerment and efficiency of care from a patient perspective and an improvement in their experiences with their care [22]. In addition, patients' adherence to the symptom reporting tool was relatively high, and both patients and providers were satisfied with the application, providing positive feedback related to ease of use, functionality, and information provided within the application. Importantly, this application enabled a form of participatory medicine in which patients could report their symptoms daily to physicians and initiate more frequent and timely conversations about their care based on their symptoms on a given day. Patients were trained in viewing their daily integrated symptom deviation scores, which could help inform and validate their decisions to reach out; in addition, they were shown how to access data records of their symptoms for up to 30 days prior. These features could serve as important tools to empower patients in their discussions with their physicians and their share of decision-making $[22,23]$.

\section{CONCLUSIONS}

In this feasibility study of the COPD Co-Pilot application, patient adherence to the use of this tool was high overall, indicating patients' willingness to monitor their symptoms daily. Although a limited number of participants initiated PCP contact during this study, those who used the study-provided toll-free number in the application to initiate contact waited for a substantially shorter median time for their provider to issue a clinical recommendation compared with those who used other means of contact. The results of this study suggest that use of this application in a primary care setting could empower patients to better manage their COPD and may help PCPs respond to patients more efficiently. Further evaluation is therefore warranted to better understand how this tool can facilitate a model of participatory medicine in COPD and improve health care outcomes.

\section{ACKNOWLEDGEMENTS}

The authors thank the patients and investigators for their participation in this study. The authors would also like to acknowledge Jill Davis and Melanie Morris of AstraZeneca for providing study support. The term "COPD CoPilot" is a registered trademark.

Funding. The journal's Rapid Service Fee was funded by AstraZeneca.

Medical Writing and/or Editorial Assistance. Medical writing support was provided by Shane Walton, PhD, of Cello Health Communications/MedErgy (Yardley, PA, USA) in accordance with Good Publication Practice (GPP3) guidelines and funded by AstraZeneca.

Authorship. All named authors meet the International Committee of Medical Journal Editors (ICMJE) criteria for authorship for this article, take responsibility for the integrity of 
the work as a whole, and have given their approval for this version to be published.

Author Contributions. All authors (Gerard J. Criner, Therese Cole, Kristen A. Hahn, Kari Kastango, James M. Eudicone, and Ileen Gilbert) made substantial contributions to the study's conception, design, data acquisition, analysis, and/or interpretation; participated in drafting the manuscript or revising it critically for substantial intellectual content; agreed to submit the manuscript to this journal; gave final approvals of the submitted version; and agreed to be accountable for all aspects of this publication.

Prior Presentation. Portions of this study were presented on a poster titled "A feasibility study to examine real-world use of a daily digital chronic obstructive pulmonary disease (COPD) respiratory symptom tracker in a primary care setting" at the American Thoracic Society (ATS) International Conference, May 17-22, 2019, Dallas, TX, United States.

Disclosures. Gerard J. Criner has received research grants from AstraZeneca, Boehringer Ingelheim, Novartis, Respironics, MedImmune, Actelion, Forest, Pearl, Ikaria, Aeris, PneumRX, and Pulmonx; is the founder of, and has equity interest in, HGE Health Care Solutions, Inc., and HGE Technologies; and has consulted for Amirall, Boehringer Ingelheim, and Holaira. Kristen A. Hahn is an employee of IQVIA, which was contracted by AstraZeneca to collect and analyze study data. Therese Cole and Kari Kastango were employees of IQVIA at the time this study was conducted. James M. Eudicone and Ileen Gilbert are employees and shareholders of AstraZeneca.

Compliance with Ethics Guidelines. This study was reviewed and approved by the Copernicus Group Institutional Review Board, under an abbreviated investigational device exemption as described within applicable Food and Drug Administration regulations. Because all study sites were in the United States, this approval was sufficient for all participating study sites. The study was conducted in compliance with the principles of the Declaration of Helsinki and Good Clinical Practice guidelines. All subjects provided written informed consent to participate in the study.

Data Availability. The datasets generated during and/or analyzed during the current study are available from the corresponding author on reasonable request.

Open Access. This article is licensed under a Creative Commons Attribution-NonCommercial 4.0 International License, which permits any non-commercial use, sharing, adaptation, distribution and reproduction in any medium or format, as long as you give appropriate credit to the original author(s) and the source, provide a link to the Creative Commons licence, and indicate if changes were made. The images or other third party material in this article are included in the article's Creative Commons licence, unless indicated otherwise in a credit line to the material. If material is not included in the article's Creative Commons licence and your intended use is not permitted by statutory regulation or exceeds the permitted use, you will need to obtain permission directly from the copyright holder. To view a copy of this licence, visit http:// creativecommons.org/licenses/by-nc/4.0/.

\section{REFERENCES}

1. Global Initiative for Chronic Obstructive Lung Disease (GOLD). Global Strategy for the Diagnosis, Management and Prevention of COPD, Global Initiative for Chronic Obstructive Lung Disease (GOLD) 2019 Report. 2019. https://goldcopd.org/. Accessed 4 Mar 2021.

2. Doney B, Hnizdo E, Syamlal G, et al. Prevalence of chronic obstructive pulmonary disease among US working adults aged 40 to 70 years. National Health Interview Survey data 2004 to 2011. J Occup Environ Med. 2014;56:1088-93.

3. Wheaton AG, Cunningham TJ, Ford ES, Croft JB. Centers for Disease Control and Prevention (CDC). Employment and activity limitations among adults with chronic obstructive pulmonary disease-United States, 2013. MMWR Morb Mortal Wkly Rep. 2015;64:289-95. 
4. Nici L, Bontly TD, Zuwallack R, Gross N. Self-management in chronic obstructive pulmonary disease. Time for a paradigm shift? Ann Am Thorac Soc. 2014;11:101-7.

5. Donner CF, Raskin J, ZuWallack R, et al. Incorporating telemedicine into the integrated care of the COPD patient a summary of an interdisciplinary workshop held in Stresa, Italy, 7-8 September 2017. Respir Med. 2018;143:91-102.

6. Hanlon P, Daines L, Campbell C, McKinstry B, Weller D, Pinnock H. Telehealth interventions to support self-management of long-term conditions: a systematic metareview of diabetes, heart failure, asthma, chronic obstructive pulmonary disease, and cancer. J Med Int Res. 2017;19:e172.

7. Shaw G, Whelan ME, Armitage LC, Roberts N, Farmer AJ. Are COPD self-management mobile applications effective? A systematic review and meta-analysis. NPJ Prim Care Respir Med. 2020;30: 11.

8. Sul AR, Lyu DH, Park DA. Effectiveness of telemonitoring versus usual care for chronic obstructive pulmonary disease: a systematic review and meta-analysis. J Telemed Telecare. 2020;26:189-99.

9. Yang F, Wang Y, Yang C, Hu H, Xiong Z. Mobile health applications in self-management of patients with chronic obstructive pulmonary disease: a systematic review and meta-analysis of their efficacy. BMC Pulm Med. 2018;18:147.

10. Li X, Xie Y, Zhao H, Zhang H, Yu X, Li J. Telemonitoring interventions in COPD patients: overview of systematic reviews. Biomed Res Int. 2020;2020:5040521.

11. Lundell S, Holmner A, Rehn B, Nyberg A, Wadell K. Telehealthcare in COPD: a systematic review and meta-analysis on physical outcomes and dyspnea. Respir Med. 2015;109:11-26.

12. Kruse C, Pesek B, Anderson M, Brennan K, Comfort $\mathrm{H}$. Telemonitoring to manage chronic obstructive pulmonary disease: systematic literature review. JMIR Med Inform. 2019;7:e11496.

13. Rassouli F, Boutellier D, Duss J, Huber S, Brutsche $\mathrm{MH}$. Digitalizing multidisciplinary pulmonary rehabilitation in COPD with a smartphone application: an international observational pilot study. Int J Chron Obstruct Pulmon Dis. 2018;13:3831-6.
14. Bowler R, Allinder M, Jacobson S, et al. Real-world use of rescue inhaler sensors, electronic symptom questionnaires and physical activity monitors in COPD. BMJ Open Respir Res. 2019;6:e000350.

15. Bentley CL, Powell L, Potter S, et al. The use of a smartphone app and an activity tracker to promote physical activity in the management of chronic obstructive pulmonary disease: randomized controlled feasibility study. JMIR Mhealth Uhealth. 2020;8:e16203.

16. Cordova FC, Ciccolella D, Grabianowski C, et al. A telemedicine-based intervention reduces the frequency and severity of COPD exacerbation symptoms: a randomized, controlled trial. Telemed J E Health. 2016;22:114-22.

17. Smith HS, Criner AJ, Fehrle D, Grabianowski CL, Jacobs MR, Criner GJ. Use of a smartphone/tabletbased bidirectional telemedicine disease management program facilitates early detection and treatment of COPD exacerbation symptoms. Telemed J E Health. 2016;22:395-9.

18. McLean S, Nurmatov U, Liu JL, Pagliari C, Car J, Sheikh A. Telehealthcare for chronic obstructive pulmonary disease: Cochrane Review and metaanalysis. Br J Gen Pract. 2012;62:e739-49.

19. Tabak M, Brusse-Keizer $M$, van der Valk $P$, Hermens $\mathrm{H}$, Vollenbroek-Hutten M. A telehealth program for self-management of COPD exacerbations and promotion of an active lifestyle: a pilot randomized controlled trial. Int J Chron Obstruct Pulmon Dis. 2014;9:935-44.

20. Vitacca M, Montini A, Comini L. How will telemedicine change clinical practice in chronic obstructive pulmonary disease? Ther Adv Respir Dis. 2018;12:1753465818754778.

21. Cruz J, Brooks D, Marques A. Home telemonitoring in COPD: a systematic review of methodologies and patients' adherence. Int J Med Inform. 2014;83: 249-63.

22. Lundell S, Wadell K, Wiklund M, Tistad M. Enhancing confidence and coping with stigma in an ambiguous interaction with primary care: a qualitative study of people with COPD. COPD. 2020;17:533-42.

23. Disler R, Appleton J, Smith T, et al. Empowerment in people with COPD. Patient Intell. 2016;8:7-20. 